\title{
Salutogenesis: The Book's Editors Discuss Possible Futures
}

\author{
Geir Arild Espnes
}

\section{Introduction}

While the previous chapters of this book have presented the history and status of salutogenesis, this last chapter has the ambition to try analyzing possible futures of the salutogenesis orientation and model-and the sense of coherence-Aaron Antonovsky's own answer to the salutogenic question.

It is always a challenge to predict the future based on what we know today. At the end of the last millennium it would have been impossible to foresee the development of the scholarship on salutogenesis we see today. Some saw the model and orientation of salutogenesis as heading on a path of being obsolete. This has not happened, as the work of the editors and authors of this book attest. Salutogenesis is also alive and well in the conversations, plans, and happenings of key health promotion organizations and networks, including not least the Global Working Group on Salutogenesis of the International Union for Health Promotion and Education (IUHPE). The Working Group is the "home" of the editorial group, and it has provided a stable arena for the extended work that the Handbook has required.

I write above that salutogenesis is alive and well, and perhaps the surest sign of the vitality of salutogenesis today is the global panoply of salutogenesis scholars from huge diverse backgrounds; just have a look through the author biographies at the close of this Section! What binds us despite the diversity? All who work with salutogenesis ideas share this: an almost desperate need for a theoretical foundation beyond the existing and limiting view of pathogenesis.

If the present healthy state of salutogenesis is reasonably well presented in this book, what about the future? This last

G.A. Espnes $(\bowtie)$

NTNU Center for Health Promotion Research, Norwegian University of Science and Technology, Trondheim, Norway

e-mail: geirae@svt.ntnu.no chapter of the book is based on a running email conversation between the editors that extended over the final months of the book's production. Invited by me to discuss the future of salutogenesis, the Section Editors did so enthusiastically: Shifra Sagy, Bengt Lindström, Maurice Mittelmark, Monica Eriksson, Jürgen Pelikan, and Georg Bauer. This email conversation, taking place in the summer and fall of 2015, was an extension of many face-to-face (and a few Skype) discussions and debates amongst the editors (including Contributing Editor Torill Bull) that have taken place at these health promotion conferences and editors' meetings:

- Vancouver, Canada (IUHPE World Conference), June 2007.

- Helsinki, Finland (First International Research Seminar on Salutogenesis), May 2008.

- Helsinki, Finland (Second International Research Seminar on Salutogenesis), May 2009.

- Geneva, Switzerland (IUHPE World Conference and Third International Research Seminar on Salutogenesis), July 2010.

- Trollhättan, Sweden (Fourth International Research Seminar on Salutogenesis), May 2011.

- Trondheim, Norway (Fifth International Research Seminar on Salutogenesis), August 2012.

- Tallinn (Nineth IUHPE Health Promotion Conference), September 2012.

- Jerusalem, Israel (Handbook Editors' Meeting), April 2013.

- Tønsberg, Norway (Nordic Health Promotion Conference), June 2013.

- Bergen, Norway (Handbook Editors' Meeting), AprilMay 2014.

- Trondheim, Norway (Second International Forum for Health Promotion Research), August 2014.

- London (Handbook Editors' Meeting), November 2014.

- London (Handbook Editors' Meeting), May 2015. 
Given the extensive interaction over the course of the past 8 years, it is not surprising that the editors managed the quite direct and familiar tone that readers will note in the email discussion recounted below! To launch the email discussion, I initially posed four questions about the future of salutogenesis. The editors had a chance to read and reflect on one another's responses, then write addition thoughts, and this was repeated several times. The exchanges are cited verbatim (except for some formatting changes), preserving the informal and collegial atmosphere that we are privileged to enjoy (Fig. 49.3).
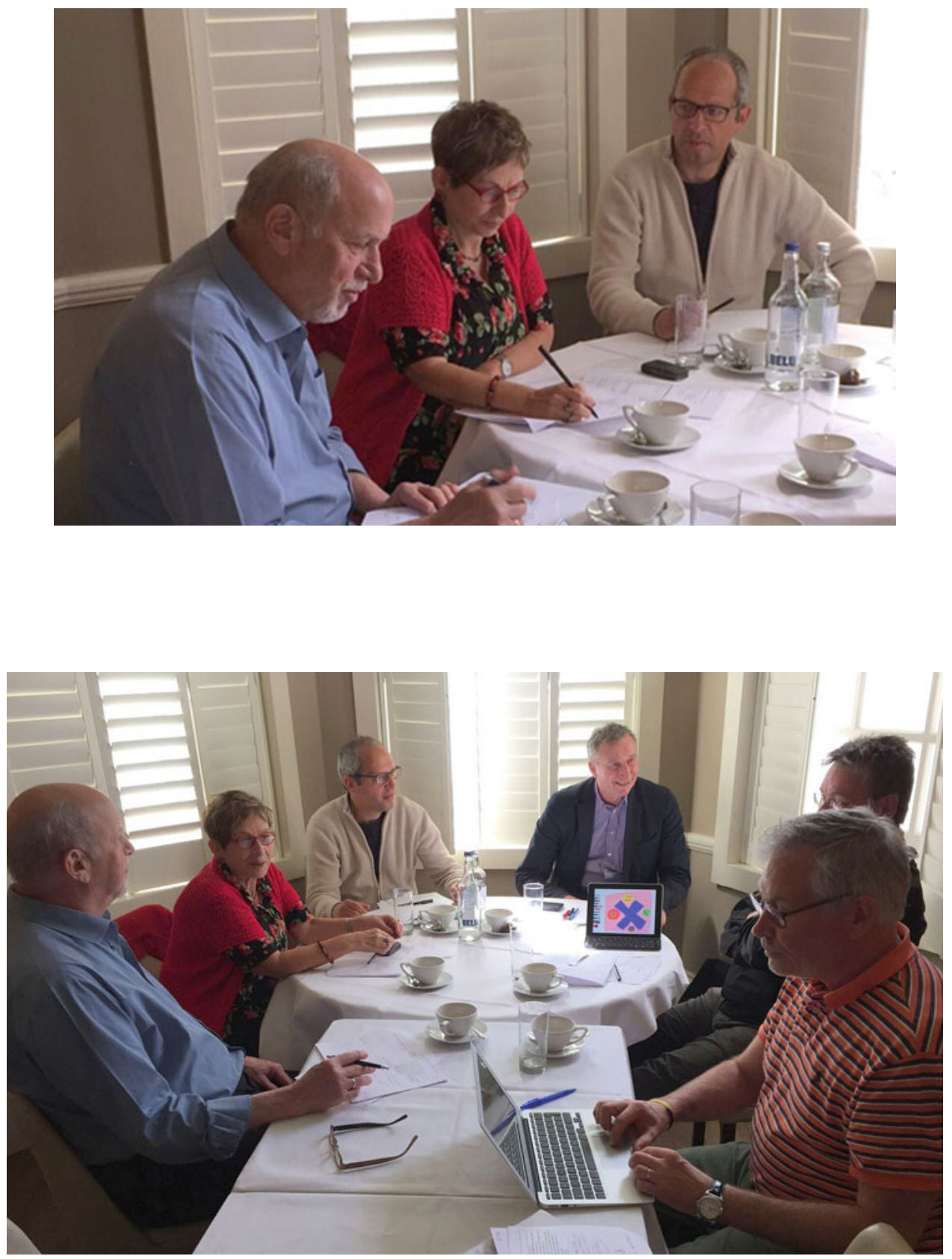


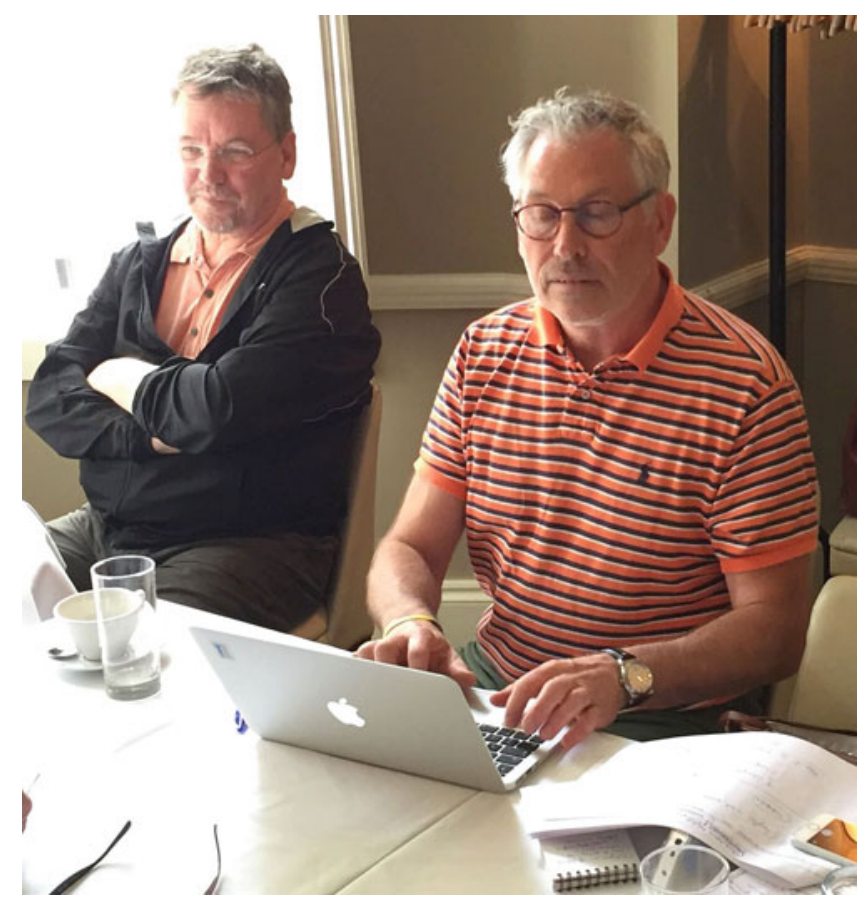

\section{Geir A. Espnes Starts the Conversation}

Let us start with a question that several discussions among us have touched on-health definitions. Is the future work on salutogenesis in need of an explicit definition of "health"? Let us first hear a former PhD student of Aron Antonovsky reflect on that question.

\section{Shifra Sagy}

I do not think salutogenesis is in need of a new explicit definition of "health." First, the core idea of salutogenesis is not to study the states of our human being at the two poles of "health" and "disease," but to study our existence on the continuum of "ease-disease." I trust that explicit definitions of the poles will be in contrast to this main basis of salutogenesis. I deeply believe we should leave the strict definition of health to other paradigms and be more attentive to the subjective evaluation of one's place on the continuum.

Second, as a project coordinator of Antonovsky's longitudinal research of the retirement transition (see Antonovsky, Sagy, Adler, \& Visel, 1990; Sagy \& Antonovsky, 1992), I was aware of his apprehension of the danger of tautology (Antonovsky, 1992) and the possibility of contamination between the two indicators: sense of coherence and health. In that "old" project we selected four facets that seemed to be common to all states of health: pain, functional limitation, and prognostic and action implications. This operational definition, based mainly on self-definition and embedded in one's cultural context, is still considered by me as the most appropriate definition of health in the framework of the salutogenic paradigm.

\section{Geir}

Thank you Shifra-Bengt what are your reflections of the need of a specific health definition?

\section{Bengt Lindström}

My responses are NO and YES. NO in terms of Antonovsky's quest 'What creates health?' and the pursuit of what factors and processes create health-not health as such, but processes leading to health. In that sense, health could be undefined. However YES in terms of the fact that the evidence on his sense of coherence theory speaks for a strong connection to the dimension of well-being; quality of life, and mental health, but also indirectly to physical health since people with a strong sense of coherence manage physical limitations better. The construct as such is a social construct that relates to coherence between individual, group, and society, i.e., various social dimensions, thus 
social health, and finally it is embedded in the fourth dimension of health of meaningfulness, existential health. For academia and research we definitely need to define the concepts we are working with. Therefore definitions such as health are needed also when we try to bend the curve and define the processes leading to better health, not what causes disease Antonovsky's concepts are directing the processes towards life, not merely counteracting risks, death, and disease as in the biomedical model.

\section{Maurice Mittelmark}

No! I have tried to address this very pointedly in Mittelmark and Bull (2013). I quote:

\begin{abstract}
"Rather than try to arrive at consensus for the health concept for health promotion research, we suggest that health promotion adapt a pragmatic approach accepting various conceptualisations and measurement approaches. We are quite happy to settle for a diversity of approaches, with well-founded conceptualisations of various aspects of health. This 'tapas table' rather than 'single dish' approach, which is the present reality, has led to a rich, varied empirical production of health promotion research. This varied production may well be seen as enriching - a variety of perspectives generally adds depth of understanding to a motif. Put another way, it is not only pragmatic, it is innervating, to accept that what researchers define as health is health, in the research context."
\end{abstract}

\section{Geir}

That was a pretty clear and strong point of view from Maurice, Monica what is yours?

\section{Monica Eriksson}

The vast majority of people are talking about health in a broad perspective. Therefore it would be a more important position to use the word well-being and define it, instead of the narrower concept health. At the same time, we must be aware that most people mean well-being when they talk about health and feeling good. The definition is also important in relation to health promotion. Today there is still the perception that preventing disease is the same as promoting health. Unfortunately there is still a need to explain health in the sense of salutogenic understanding.

\section{Jürgen Pelikan}

And I say: Yes, definitely! It is important to have a unifying paradigm (sensu Kuhn) with explicit definitions and understandings of core concepts and clearly defined operationalization of these for a field to be able to produce comparative and cumulative researchSee, knowledge, and experiences. Only explicit definitions will allow scientists to relate to others theorizing empirical results, and this is an example of a precondition for doing sound literature reviews.

Of course, that does not mean that there has to be consensus on just one definition of health by all researchers of the field, even if that would be ideal for easy communication, cooperation, and coproduction of knowledge. There can be and will be different definitions, but these have to be explicit and it has to be clear exactly which one is used in a specific context of research or publication or practice.

For the field of salutogenesis, but also for other kinds of health sciences or practices, be it health care, health promotion, or public health, health definitely is a core concept, which has to be clarified and explicitly defined to allow cumulative research and knowledge production within and by a community of health scientists. In the case of the paradigm of salutogenesis, one underlying assumption is that health is produced or reproduced by a process or a multitude of processes, as diseases are by pathogenesis. Without a clear understanding of "health," salutogenesis cannot offer an adequately complex description of these salutogenic processes and their most important mechanisms.

For using the concept of (positive) health as a quality which is important for and can be observed on and by living, especially for human beings, it is important to be clear on how health differs from concepts like illness/sickness/disease, what kind of dimensions (e.g., physical, mental (including spiritual), social) and aspects (e.g., wellfunctioning, well-being, attractiveness) can be differentiated and how subjective lay and "objective" expert observations of health can be taken into account. I have made some propositions for that, which are published (Bauer, Davies, \& Pelikan, 2006; Pelikan, 2007, 2009; Pelikan \& Halbmayer, 1999) and can be followed or criticized. Of course, depending on the context and goal, health sciences and salutogenesis can and will work with either more narrow (clinical) or rather wider concepts of (public) health. As long as this is made transparent or even better also explicitly reflected on and argued, I see there is no problem for the future of salutogenesis. But to have a better future than the past, it would help if we supporters of salutogenesis would define more explicitly what specifically is meant by "health," which seems to be in the center of the paradigm of salutogenesis.

\section{Geir}

Georg, you are the last one to reflect on the need for a health definition that is based on a salutogenic theory-what do you say? 


\section{Georg Bauer}

I say: Yes, otherwise we stay within the pathogenic framework or claim to promote health as something more than the absence of disease without a clear understanding of what we actually pursue. As illustrated throughout the book, most salutogenesis scholars consider the focus on positive health outcomes as a constituting element of the salutogenic orientation. Health promotion practice equally aims for promoting positive health. However, for now the salutogenic model only offers a vaguely defined easedisease or order/disorder continuum and it has been justifiably questioned whether a continuum is the best conceptualization of the relationship of disease and health. Thus, to counter-balance the clear conceptualizations and measures of disease-related "health" outcomes, we urgently need clear definitions and measures of positive health. As positive health is about pursuing a self-determined purpose in life, it will be reasonable to develop life-domain-specific measures thereof.

\section{Maurice}

It may seem at first blush that we have three answers: yes, no, and yes-and-no $\odot$. But I do not see it that way:

It seems Shifra agrees that a single definition is not needed, at least not a new one. She argues for AA's original definition, the ease/disease continuum. She states that operationally, people will define their health in various ways depending on self-perception and culture. Then we have to accept various definitions of health.

Bengt calls for a focus on processes, but seems at ease with various ideas about the meaning of health as long as they are well-operationalized. I interpret him this way because he mentions various dimensions of well-being, and various dimensions cannot all be operationalized in a singular way. I read Monica as in agreement with Bengt, that wellbeing is a broad construct, and that we do not need to define a "narrower" concept of health.

On to Jürgen, he answers the question "yes," but goes on to specify that multiple definitions are perfectly acceptable as long as each is well-operationalized. Is that not really a "no" answer? I answer "no," but I surely agree that various definitions, which I encourage, should be welloperationalized. Do Jürgen and I not agree?

Going on to Georg, who answers "yes," he actually calls for various definitions, for example, a definition of positive health that stands apart from the pathogenesis conceptions of health. If he accepts that we must live with health sometimes defined as disease and disability (a realistic position), and that we are in need, in addition, of a definition of positive health, Georg seems willing to accept at least two definitions of health. So, his answer to the question is actually "no," in agreement with Shifra, a reluctant Jürgen, and an enthusiastic me.

Adding this all up, I think we are in agreement that health must be allowed to be defined in various ways, that health promotion needs to focus on positive concepts of health and well-being, and that whichever way a particular study/ researcher defines health, it should be done rigorously. Or am I missing something?

\section{Georg}

Thanks Maurice, nice integration. Because I suggested lifedomain-specific measures of positive health, I even support more than two definitions of health. As we probably all agree, that in the future, we do not need "an" explicit definition of health, but several, we should initiate discourses about diverse, culture-specific definitions of health for different purposes and contexts. Ideally, this discourse and formulating definitions should not only include researchers, but also those whose health we like to measure and improve.

\section{Geir}

Let us turn to the next question in this reflection on salutogenesis: Do we think that salutogenesis is important to positive health developments, and not only to cope with stressful life situations? Can salutogenesis be lifted out of the misery thinking about health? Let us keep the same order in reflections for this one.

\section{Shifra}

If we accept the above definition of health, we should see, of course, salutogenesis as a meaningful conceptual framework to positive health developments. Moreover, salutogenesis in its core idea does not relate to stressful life situations only, but to the whole spectrum of human existence. In this way of understanding the salutogenic paradigm, no doubt it should include (and maybe enhance its interest) in positive health.

\section{Bengt}

Looking at the evidence, again, outcomes regarding people and systems that develop a strong sense of coherence clearly speak for improvement of health in all four dimensions. However, health as such is an asset, a resource 
for life and in its character "positive." You know, I would never use the concept "positive health" because health as such is already positive. Only for pedagogical reasons can I use that construct. Also, stress needs to be considered here because stress is not to be seen as a negative condition, which the question implies. I therefore find two useless constructs in this question.

\section{Maurice}

To my opinion, the salutogenic model of health is not very helpful, while the more general salutogenic (assets for health) concept is helpful, but only in a very general way.

\section{Monica}

Yes, salutogenesis is important in view of positive psychology and the focus on well-being. The important thing is to explain that salutogenesis is so much more than Antonovsky's sense of coherence, it is a question about identifying and using the strengths of people at the same time you identify deficits and shortcomings and facilitate these. Even more important is to explain that there is no contradiction between a pathogenic and a salutogenic approach. As I see it, and also write in the book, salutogenesis is an area of knowledge, an approach, a way of learning, and working.

\section{Jürgen}

In rich post-modern health society it is assumed that also (positive) health, by becoming doable and technically feasible, can be intentionally enhanced, and not just disease is manageable and preventable by specific action. Therefore development of (positive) health has become an individual and societal issue, a remarkable asset on economic markets and a topic in public policy. Thus the question arises if salutogenesis, or more specifically for e.g., a high SOC, has more to offer than being a resource for successfully coping with omnipresent stressful life situations. This was an important motive of the original invention and development of this paradigm by Aaron Antonovsky in the past. But in the future, to be more relevant for all ongoing discourses on health, salutogenesis should demonstrate and publicize also its remarkable potential for developing positive health.

I think, as an answer to the second part of the question, salutogenesis can lift itself out of the misery thinking about health, when it really emancipates itself from the dominant medical focus on managing disease and individual risk factors (correctly the specific contribution of clinical science and practice to maintain health), and more radically starts to orient its research and practice at improving (positive) health and well-being by focussing on salutory factors and (positive) health outcomes in research and health promotion practice.

\section{Georg}

If we narrowly follow Antonovsky's conceptualization, salutogenesis is about coping with miserable life situations or about "surviving the toxic river of life"-leaving little space for looking at the bright side of life. Applying salutogenesis to positive health development-or joyful swimming in the river of life-is urgently needed.

Conceptually, Antonovsky only made half the paradigm shift: he moved from single disease risks to generalized resistance resources and from single disease outcomes to the ease/disease continuum. Now, we need to expand the role of resources to be also a source of immediately positive life experience-and good for resistance against stressors. On the outcome side, we need to consider that positive health is more than the absence of disease (pathogenesis) or just being at ease/order (salutogenesis a lá Antonovsky)_but includes aspects like actively pursuing a self-determined purpose in life, flourishing or happiness. Such a salutogenic model completed by positive health development will correspond to how health promotion practitioners and researchers already have adopted salutogenesis as mentioned above: as a full paradigm shift towards resources and positive health. This is reflected by the WHO Ottawa Charter of health promotion (1986) which defines health as a "... positive concept emphasizing social and personal resources, ... to reach a state of complete physical, mental, and social well-being." So if we intend to serve health promoters as the primary stakeholders using and disseminating salutogenesis, we better develop this concept to include positive health development.

Further, such completed salutogenic models will much better correspond to real-life experience. Surely, our life is partly stressful and sometime miserable-but also in large parts joyful. If we acknowledge that "health is created and lived by people within the settings of their everyday life; where they learn, work, play, and love" (WHO, 1986) we should also be able to study and promote joy, growth, thriving, and flourishing of this everyday life experience. This will lift us out of a paternalistic approach to ameliorate miserable lives to supporters of self-determined living. 


\section{Georg}

So, overall we all seem to agree that salutogenesis could be important to positive health developments, although we name the desired outcome differently: positive health (Shifra, Jürgen, Georg), health as an asset/resource of life (Bengt), assets for health (Maurice), well-being (Monica). Referring back to the above suggested discourses on definitions of (positive) health, it will be interesting how far these differences in terminology also reflect different conceptualizations of positive health development. Another open issue is if "positive health" only becomes "doable and technically feasible" in a rich post-modern society as suggested by Jürgen. Or if we shouldn't acknowledge that probably most if not all human beings even in poorest societies have at least some positive health experiences on an everyday basis. This would urge health promoters in all contexts to always simultaneously study and address both misery/disease and joy/health as coexisting sides of the human health experience.

\section{Maurice}

I like Georg's summary and I think that he does well in capturing the essence of our contributions on this question. Regarding the possibility of positive health in non-rich, non-post-modern settings, a firm tenant of the positive deviance (optimal outlier) approach to health promotion is that in all settings, even the harshest, there are people who manage to thrive (positive health), and the challenge is to learn from them, while NOT accepting the inevitability of harshness.

\section{Geir}

Thank you, all of you. Let us than turn to the third of our four questions: Antonovsky made a proposition years ago: salutogenesis should be a theory for health promotion. Why has this not happened? How can salutogenesis be more than an idea at the edge of the universe? Georgwhat do you say?

\section{Georg}

The main problem is that the salutogenic model as developed by Antonovsky only is a partial model for health promotion. Primarily, he developed a model around the sense of coherence (SOC) which is a challenging combination of the psychological concept of the sense of coherence and the physical or biophysiological concept of (negative) entropie or (dis)order underlying his (dis-) ease continuum. This creates the deadlock situation that most empirical salutogenesis research sticks to sense of coherence as a personal health resource that unfortunately provides little guidance to the settings or whole systems approach of health promotion. In this situation, the field of health promotion practice turns to the general salutogenic orientation-legitimizing the focus on resources and positive health outcomes without providing an appropriate theory.

To completely cover the positive side of health development in the future, the salutogenic model should be expanded to include all three biopsychosocial processes of health development. Further, as suggested above, the outcome side of positive health also needs to be clearly defined and measured beyond the vague (dis-) ease continuum. Only then, salutogenesis fulfills the promise to be not the mere mirror-term but mirror-concept of the welldefined concept of pathogenesis that already covers the full range of biopsychosocial disease development. In the future, salutogenesis should be integrated into a complete health development model as suggested earlier (Bauer et al., 2006) that can grasp the full human health experience and the relationships between salutogenesis and pathogenesis.

\section{Shifra}

I trust salutogenesis is not "an idea in the edge of the universe." For me it is in the midst of the research of health and social sciences, but has its representations in different concepts and models (see for example, our chapter on positive psychology and salutogenesis in our Handbook). The same answer is relevant when we relate to health promotion. Another explanation for health promotion could relate to the broad scope of salutogenesis. It appears that research in health promotion, as in health in general, is based more and more on ad-hoc, reduced and limited theories, and not on wide, comprehensive theories.

\section{Jürgen}

To answer your question Geir, we have to proof first if we do agree on its underlying assumption that adequate reception of salutogenesis as a theory in health promotion (research, practice, policy) has not happened since 1994 or 1996. The different chapters of this Handbook give a rather differentiated answer to this assumption, which of course 
depends on criteria used for looking at the evidence for this assumption, e.g., lip service to salutogenic orientation, use of salutogenic model, or of the concept and instrument of SOC.

But if we accept the assertion of failure, there are two or three different kinds of answers to this question. We either can attribute the failure to the quality of salutogenesis as a theory or to the perception and acting of the health promotion community, or both. Either salutogenesis has not been offered as a theory at all, or it is not an adequate theory for health promotion, or the health promotion community is not aware enough of salutogenesis as a theory, or is not interested at all to have a grand underlying theory. Or the failure can be attributed to a mixture of these deficits.

Indeed, I have the impression that there is not yet a real theory of salutogenesis. There definitely exists a paradigm offering some basic assumptions for a salutogenic orientation, but that may be too loose and too general to be a powerful theoretic orientation for health promotion. There also exists a salutogenic model, but this very complex model has not even been taken up by Antonovsky in his later writing himself or by nearly anybody else as well (cf. Mittelmark \& Bull, 2013); in a way this model seems to be a dead end. Of course, there is the sense of coherence as a concept and instrument which has been taken up widely also by researchers which would label themselves as health promoters. But the sense of coherence is a much too narrow and biased concept to serve as a theoretic foundation of health promotion as a field. It just is one of many pieces in a more universal theory of salutogenesis. With these weaknesses of salutogenesis in mind it is not so surprising that the community of health promoters did not take up salutogenesis enthusiastically as its foundation.

Thus, for salutogenesis to be more than an idea at the edge of the universe, the community of salutogenic researchers has to put its forces together, preferably in cooperation with health promoters, to work on the missing salutogenic theory. The knowledge collected in this Handbook will be a perfect basis for this endeavour.

\section{Bengt}

When the Ottawa Charter came it was a political-policyprinciple statement without a theoretical foundation and in the enthusiasm, theory was forgotten (although maybe considered as Kickbusch said last year); this has been the Achilles heel of health promotion. You can run in any direction and base it on whatever you like and call it health promotion. Many just continued as before but labelled it health promotion. Antonovsky's attempt to lead a discussion on the matter with the core of health promotion [experts] at WHO Copenhagen, in August 1992 was well received. However his sudden death never made it possible to follow it up. As you know we now have made strong efforts to show how well they match each other (Figs. 49.1 and 49.2). There is a need for theoretical underpinning to make health promotion researchable and comme il faut on the Parnassus of Science. Without theory we do not know what we do or what to measuresalutogenesis suits health promotion and sense of coherence both ideologically and theoretically. I also think a lot of people never have integrated and understood the essence of salutogenesis.
Fig. 49.1 Health determinants, settings and life experience, and quality of life

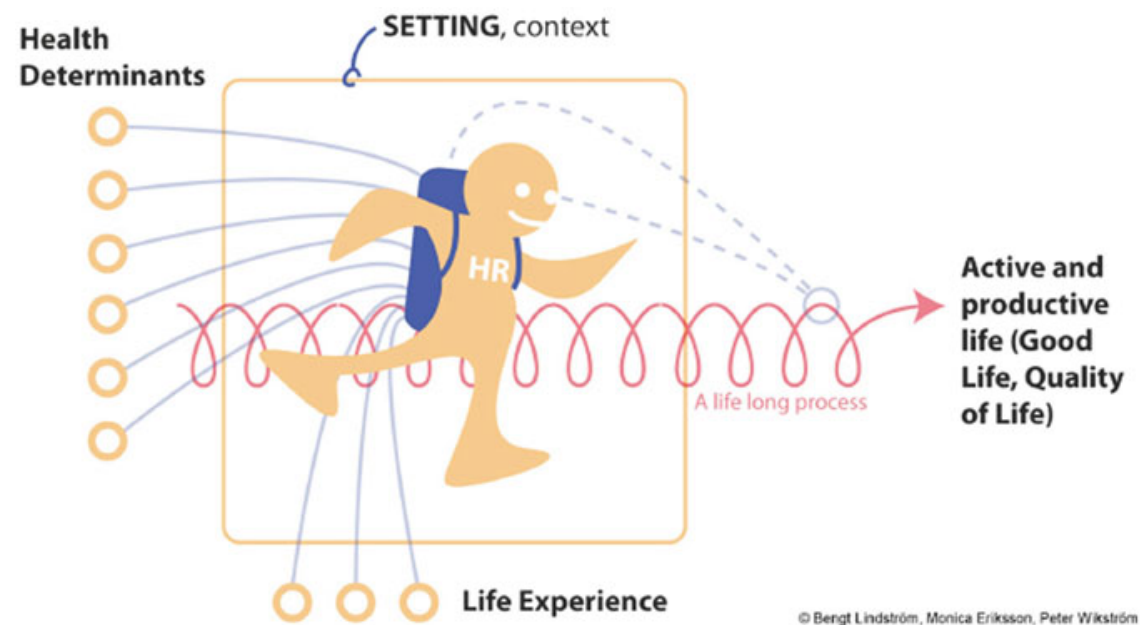


Fig. 49.2 Generalized resistance resources, life experience, and quality of life

\section{BUILDING BLOCKS FOR HEALTH PRMOTION PROCESSES and SALUTOGENIC PROCESSES/CONCEPTS}

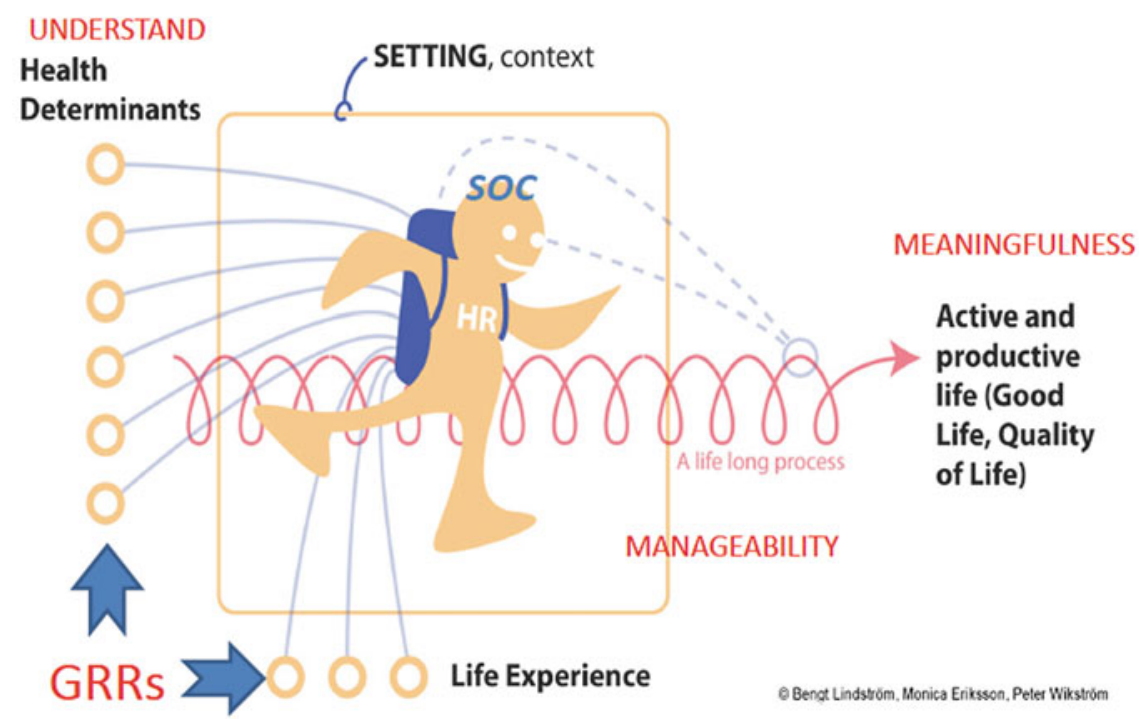

Fig. 49.3 The editors met at Jerusalem in April 2013

\section{Workshop - Salutogenesis book \\ Jerusalem, April $18^{\text {th }}-20^{\text {th }}$}

Thursday, April $18^{\text {th }}$

- 16:00-17:30 Introduction round; Update, activities of the IUHPE Global Working group on Salutogenesis

- 17:30-19:00 Short Skype meeting with publisher Khristine Queja (Springer) in New York; Overall organisation of the book

- 19:00-21:00 Dinner, walking tour in Jerusalem

\section{Friday, April $19^{\text {th }}$}

- 9:00-13.00 Chapters' placements in Sections and chapter lengths; Proposed new chapters; Authorships and first authors; Editors' roles and responsibilities

- 13:00-16:00 Lunch and rest

- 15:00-19:00 Page proofs - authors and editors responsilities; Publication model; Production time line

\section{Saturdav, April $20^{\text {th }}$}

- 9:00-13:00 Instructions to authors; Distribution of author's copies; Book and SWG issues arising

- 13:00-15-15:00 Lunch and rest 


\section{Maurice}

When I interpret your question, I interpret it in this way: Can the power brokers in the health arena (the doctors and the healthcare estate) ever take Salutogenesis seriously? I have my doubts. Misery pays the bills, not happiness. No one visits the doctor to increase their happiness. So, the answer is no, in the medical sciences: no one visits the doctor to increase their capacity to cope with life. However, if we can get the social sciences interested, the answer could be yes... just see what positive psychology has done to help liberate psychology from its (modern) selfidentity with illness.

\section{Monica}

When Antonovsky suggested the salutogenic theory I strongly believed, he hoped that the theory would be the basis for health promotion. Why not happened to a greater extent can only be answered by leading representatives of the health promotion movement. Kickbusch said in Trondheim in 2014 (Second International Forum of Health Promotion Research) that they "forgot" to discuss the theoretical basis for health promotion when the Ottawa Charter was drafted. It is never too late to rise up early ... it's everyone's duty to initiate the issue again in different contexts, at different levels and to different groups of people, particularly in policymaking. I do not agree with the statement that salutogenesis has not been accepted and implemented in practice. There are fields and areas where the salutogenic approach has been implemented, but not systematically, we have no overview of that, we need to systematically investigate, collect data, and describe the situation. As far as we do not have this kind of picture we feel that the salutogenic approach is not implemented at all. In addition, salutogenesis is more than a philosophical issue about the health continuum.

\section{Maurice}

I can see now, after having read the others' comments, that I should have clearly separated my thinking along the lines of the two questions. First, why has salutogenesis not become the theory for health promotion? My answer is that health promotion is a transdisciplinary arena of research, policy, and practice, not an academic discipline, and that no academic theory can dominate in a truly transdisciplinary community. Therefore, the answer to the question, how can salutogenesis be more than an idea at the edge of the universe, is another question: where in our transdisciplinary universe do we wish to see salutogenesis positioned?
At the center, as AA championed? As each person's position is her center, we could never hope that salutogenesis would be understood by a large majority of health promoters to be at the center. There are many ideas about where the center is/should be... and that is how is should be and must be. Even we salutogenesis enthusiasts occupy only approximately similar positions in the universe. Salutogenesis can never be THE theory of health promotion. Neither is it at the edge of the universe. It has a centered position for everyone writing this book. The club of enthusiasts is growing, but it will always be just one club amongst many.

\section{Georg}

Well Maurice, the only problem is that Antonovsky has chosen the mirror-term salutogenesis to claim that his/this theory is the mirror-concept of pathogenesis-and raised the hope that this theory would support a paradigm shift away from pathogenesis. Thus, salutogenesis is out there as more than just "one academic theory." As reflected in this book, salutogenesis indeed has been happily received by many health promotion researchers and practitioners at least as providing a central, salutogenic orientation. To me the challenge remains how to advance salutogenesis from a fuzzy orientation towards a sound, transdisciplinary theory base for health promotion-allowing for diversity of approaches.

\section{Geir}

Thank you Georg. Let us then turn to the last question before we wrap up the chapter. This question is a many-faceted one-but let us hear your reflections: Is there a future for salutogenesis in disciplines, or in interdisciplinarity? Medicine? Psychology? Sociology? Technology? Ecology (climate change)? Is there salutogenesis without a sense of coherence? Is there sense of coherence without salutogenesis? Maurice, how do you see this?

\section{Maurice}

Well, health promotion is still mostly about risk factor reduction, even if the rhetoric is loftier. I think the best chance is a model like Bauer et al.'s (2006) model combining pathogenesis and salutogenesis: making a health promotion theory that is sufficiently inclusive to attract many in the field. Such a model could, I guess, also make inroads in medicine. When it comes to a future for salutogenesis: not as the salutogenic model of health... it is dormant. But the 
salutogenic umbrella could be used in many disciplines as a broad concept for positive approaches to improving social life. On salutogenesis without sense of coherence I will say this: people are already writing about a "theory of the sense of coherence" and I think the sense of coherence now has a good life of its own... it does not need the "mother salutogenesis" to survive and even thrive. Also, the salutogenic concept (umbrella) can do well without the sense of coherence. My answers are yes, and yes.

\section{Monica}

As I see it, this question is a wrong question-there is no future without the salutogenic perspective. Likewise salutogenesis is more than the sense of coherence. We know today that the sense of coherence is a multidimensional construct, i.e., consists of more dimensions than the three that Antonovsky mentioned. There is a potential to explore and implement them in health promotion and disease prevention. A new area in my opinion is to position salutogenesis into sustainable development, in particular how the social dimension of sustainable development can be related and benefit from the salutogenic framework. Equity and health equality are two of the most pertinent issues when talking about social sustainability.

\section{Jurgen}

Yes, but only if salutogenesis becomes a more disciplined field itself first, with a wider theory and a broader repertoire of methods and instruments. Then it will have more to offer to be a respected partner in joint work with other more developed disciplines. These disciplines definitely lack a sound, complex, and sophisticated perspective on (positive) health. Therefore there will be sufficient demand for that supply, (even if medicine suggests to already have the answers), since health in the future is becoming an even more prominent issue and problem individually, collectively, and globally under the difficult conditions of late modern world society at our endangered planet.

To the two more narrow questions my answer is, there is some overlap of the two concepts, the sense of coherence can be understood as a subset or element of the wider set of salutogenesis, but since salutogenesis is either a rather loose paradigm or a very complex model, and there are different partly contradictory hypotheses about the nature or impact of the sense of coherence already by Antonovsky, it is difficult to have a good systematic understanding of the relationship of the two. But empirically it can be observed that a concept like the SOC, which offers an operationalized instrument, a technology in the sense of Perrow, ${ }^{1}$ can have a successful career in science and practice, while its underlying paradigmatic background sinks into oblivion.

\section{Georg}

Human health and its development are clearly multidimensional biopsychosocial phenomena happening anywhere from submolecular to global socioecological levels. Only a transdisciplinary conceptualization of health and of health development processes building on the actual, rich human health experience can grasp this complexity. As argued above, a completed salutogenic model can at least cover the positive side of health development. Currently, the single-minded or sometimes even simple-minded focus on sense of coherence as seemingly being the main or only answer to the salutogenic question currently constrains this potential of salutogenesis. At this time, it could help to ignore the sense of coherence for a while to trigger fresh ideas and results around salutogenesis as a complete, socioecological systems theory of health.

\section{Geir}

Finally Shifra, how do you see it: Is there a future for salutogenesis in disciplines or interdisciplinarily?

\section{Shifra}

Here we come to the solution (in my eyes). At the dawn of the third millennium, interdisciplinary research is a new challenge for scientific endeavor in general (e.g., Gruenwald, 2014) and particularly for salutogenesis. I trust that the future of salutogenesis lies in "allowing" it to develop beyond health and to move towards an interdisciplinary study. Moving beyond the perspective of salutogenesis as a model that focuses on health to a paradigm that can explain other aspects of life (social relations, ecology and geography, technology, conflict studies, and others) can give a new growth.

\section{Geir}

Are there any concluding remarks on the future of salutogenesis? Shifra, you first.

\footnotetext{
${ }^{1}$ Charles B. Perrow is an emeritus professor of sociology at Yale University.
} 


\section{Shifra}

Aaron developed the concept of the sense of coherence as HIS own answer to HIS salutogenic question-who is the successful "coper" (with life or with a specific stressful situation). The sense of coherence, and its useful measurement tool, has become the most well-known concept of the salutogenic paradigm, sometimes even without any reference to the theory. However, Antonovsky himself saw the sense of coherence as only one possible answer to salutogenic questions. It is our mission in the future to broaden salutogenesis beyond its common question of stress-health relationship to include other salutogenic questions and to look for other answers as well. Thinking in a new interdisciplinary view about new salutogenic questions will bring salutogenesis to a new stage which will better fit our new millennium.

\section{Monica}

We have to continue to emphasize, examine, explore, and further describe salutogenesis and its core concepts to be used in policymaking and health promotion. Theoretical considerations and explanations are still needed, the theory needs to be further developed and expanded, i.e., relate it to other similar constructs and theories. There is a need for a systematic overview how this framework has been implemented in different contexts; the picture is to date unclear.

\section{Georg}

Our diverse perspectives raise hope that there will be diverse futures for salutogenesis: continuing to be used as an umbrella/perspective/orientation in the health sciences; expansion of its application to other interdisciplinary fields such as sustainable development, social relations, geography, etc.; and last not least as a sound, completed theory covering the full range of health experience of human beings. The last development is urgently needed to fortify the flourishing field of health promotion with a sound, diverse theoretical, and empirical basis.

\section{Geir}

Jürgen, you will have some of the last words in this discussion. Can you sum it up?
Jurgen

As I see it, salutogenesis continues to be a needed and resourceful paradigm for research, practice, and policy of health and for tackling the health gap in the twenty-first century. To become more influential in the future, salutogenesis has to widen, radicalize and further develop its theoretical base and methods. The knowledge collected in this Handbook will be an excellent base for this endeavour.

\section{Shifra}

It is wise to see models, theories, constructs, and even ideas as heuristic devices, not as holy truths, as Antonovsky wrote in his last paper (Antonovsky, 1996, p. 246). I believe that our Handbook has succeeded in following this advice. This book includes not only descriptions of the theory and research focused on the past; in many of the book's chapters you can find suggestions for new productive models, constructs, and ideas, which, in a way, grow out of the salutogenic paradigm, but have a life of their own.

Salutogenesis was a deep breakthrough in thinking and research in health some 30 years ago. To think salutogenically today, however, is quite obvious. This is the point that we have to advance. I am glad and grateful that we have done it in our Handbook. I trust Aaron would have been satisfied with these developments.

If I may end with some personal words: Aaron was my unique, wise, creative, and supportive teacher. He carefully used to teach me HOW to think and compelled me to re-examine my way of thinking according to "scientific rules." He never told me WHAT to think. I hope we have succeeded in transferring this spirit to our readers.

\section{Geir}

I am truly grateful to have been part of this insightful discussion and wish us all the best of luck!

Open Access This chapter is distributed under the terms of the Creative Commons Attribution-Noncommercial 2.5 License (http:// creativecommons.org/licenses/by-nc/2.5/) which permits any noncommercial use, distribution, and reproduction in any medium, provided the original author(s) and source are credited.

The images or other third party material in this chapter are included in the work's Creative Commons license, unless indicated otherwise in the credit line; if such material is not included in the work's Creative Commons license and the respective action is not permitted by statutory regulation, users will need to obtain permission from the license holder to duplicate, adapt or reproduce the material. 


\section{References}

Antonovsky, A. (1992). Can attitudes contribute to health? Advances, 8 , $33-49$.

Antonovsky, A. (1996). The salutogenic model as a theory to guide health promotion. Health Promotion International, 11(1), 11-18.

Antonovsky, A., Sagy, S., Adler, I., \& Visel, R. (1990). Attitudes toward retirement in an Israeli cohort. International Journal of Aging and Human Development, 31(1), 57-77.

Bauer, G. F., Davies, J. K., \& Pelikan, J. (2006). The EUHPID health development model for the classification of public health indicators. Health Promotion International, 21, 153-159.

Gruenwald, O. (2014). The promise of interdisciplinary studies: Re-imaging the university. Journal of Interdisciplinary Studies, 26, 1-28.

Mittelmark, M. B., \& Bull, T. (2013). The salutogenic model of health in health promotion research. Global Health Promotion, 20(2), 30-38.

Pelikan, J. M. (2007). Understanding differentiation of health in late modernity by use of sociological system theory. In D. V.
McQueen, I. S. Kickbusch, L. Potvin, J. M. Pelikan, L. Balbo, \& T. Abel (Eds.), Health and modernity: The role of theory in health promotion (pp. 74-102). New York: Springer.

Pelikan, J. M. (2009). Ausdifferenzierung von spezifischen Funktionssystemen für Krankenbehandlung und Gesundheitsförderung oder: Leben wir in der"Gesundheits-gesellschaft"? Österreichische Zeitschrift für Soziologie, 34(2), 28-47.

Pelikan, J. M., \& Halbmayer, E. (1999). Gesundheitswissenschaftliche Grundlagen zur Strategie des Gesundheitsfördernden Krankenhauses. In J. M. Pelikan \& S. Wolff (Eds.), Das gesundheitsfördernde Krankenhaus. Konzepte und Beispiele zur Entwicklung einer lernenden Organisation (pp. 13-36). Weinheim/München: Juventa.

Sagy, S., \& Antonovsky, A. (1992). The family sense of coherence and the retirement transition. Journal of Marriage and the Family, 54, 983-993.

WHO. (1986). Ottawa charter for health promotion. Geneva: World Health Organization. Retrieved from http://www.who.int/ healthpromotion/conferences/previous/ottawa/en/. 